\title{
Age-Related Changes in the Inhibitory Response Properties of Dorsal Cochlear Nucleus Output Neurons: Role of Inhibitory Inputs
}

\author{
Donald M. Caspary, ${ }^{1,2}$ Tracy A. Schatteman, ${ }^{1}$ and Larry F. Hughes ${ }^{2}$ \\ Departments of ${ }^{1}$ Pharmacology and ${ }^{2}$ Surgery, Southern Illinois University School of Medicine, Springfield, Illinois 62794-9629
}

\begin{abstract}
Age-related hearing loss frequently results in a loss in the ability to discriminate speech signals, especially in noise. This is attributable, in part, to a loss in temporal resolving power and ability to adjust dynamic range. Circuits in the adult dorsal cochlear nucleus (DCN) have been shown to preserve signal in background noise. Fusiform cells, major DCN output neurons, receive focused glycinergic inputs from tonotopically aligned vertical cells that also project to the ventral cochlear nucleus. Glycine-mediated inhibition onto fusiform cells results in decreased tone-evoked activity as intensity is increased at frequencies adjacent to characteristic frequency (CF). DCN output is thus shaped by glycinergic inhibition, which can be readily assessed in recordings from fusiform cells. Previous DCN studies suggest an age-related loss of markers for glycinergic neurotransmission. The present study postulated that response properties of aged fusiform cells would show a loss of inhibition, resembling conditions observed with glycine receptor blockade. The functional impact of aging was examined by comparing response properties from units meeting fusiform-cell criteria in young and aged rats. Fusiform cells in aged animals displayed significantly higher maximum discharge rates to $\mathrm{CF}$ tones than those recorded from young-adult animals. Fusiform cells of aged rats displayed significantly fewer nonmonotonic $\mathrm{CF}$ rate-level functions and an age-related change in temporal response properties. These findings are consistent with an age-related loss of glycinergic input, likely from vertical cells, and with findings from other sensory aging studies suggesting a selective age-related decrement in inhibitory amino acid neurotransmitter function.
\end{abstract}

Key words: dorsal cochlear nucleus; glycine; aging; fusiform cell; auditory; inhibition

\section{Introduction}

Age-related hearing loss (presbycusis) is a complex disorder that results in a slow deterioration of peripheral auditory input to auditory regions of the brain (Willott et al., 1991; Syka, 2002). One sequelae of age-related hearing loss is a loss of speech understanding, which has a major impact on the social and emotional health of the elderly (Thomas and Herbst, 1980; Weinstein and Ventry, 1982; Mulrow et al., 1990; Gordon-Salant and Fitzgibbons, 1993; Frisina and Frisina, 1997). The consequences of presbycusis can be described as a function of central or peripheral aging, or as a function of peripheral hearing loss. Decline in the ability to discriminate speech, especially in complex acoustic environments, likely reflects impaired processing of acoustic information within the central auditory neuraxis (Dubno et al., 1984; Moore et al., 1992; Fitzgibbons and Gordon-Salant, 1994; Schneider et al., 1994; Snell, 1997; Strouse et al., 1998; Tremblay et al., 2002, 2003; Ostroff et al., 2003). Functional and neurochemical studies in animal models suggest that sensory aging may begin as

Received June 15, 2005; revised 0ct. 17, 2005; accepted 0ct. 18, 2005.

This work was supported by National Institutes of Health Grant DC00151. We thank Drs. E. D. Young, R. H. Helfert, T. Brozoski, and J. G. Turner for insightful comments on this manuscript. We also thank Judith Bryan, Jennifer Parrish, and Deb Larsen for data collection, reduction, and helpful editing.

Correspondence should be addressed to Dr. Donald M. Caspary, Department of Pharmacology, Southern Illinois University School of Medicine, P.0. Box 19629, Springfield, IL 62794-9629. E-mail: dcaspary@siumed.edu. DOI:10.1523/JNEUROSCI.2451-05.2005

Copyright $\odot 2005$ Society for Neuroscience $\quad$ 0270-6474/05/2510952-08\$15.00/0 a slow peripheral deafferentation, which triggers a compensatory downregulation of central inhibitory amino acid neurotransmitter function (Caspary et al., 1990, 2002; Schmolesky et al., 2000; Mendelson and Ricketts, 2001; Leventhal et al., 2003). Thus, clinically observed age-related central sensory processing deficits may be attributable, at least in part, to decrements in inhibitory neurotransmission.

The present study examined age-related changes in putative dorsal cochlear nucleus (DCN) output neurons, which display a characteristic set of response properties including inhibitory responses attributable to glycinergic circuits (Voigt and Young, 1980; Caspary et al., 1987; Davis and Young, 2000). These circuits shape the output of DCN and anteroventral cochlear nucleus (AVCN) neurons (Young and Oertel, 2004). Circuits within the DCN appear well suited to encode temporally rich stimuli over a wide range of intensities even when the signal is embedded in a variety of acoustic backgrounds (Gibson et al., 1985; Frisina et al., 1994; Rhode and Greenberg, 1994; Joris et al., 2003), to preserve temporal coding in the presence of background noise (Gibson et al., 1985; Frisina et al., 1994; Joris et al., 2003). DCN neurons, including fusiform, giant, and vertical cells, receive primary afferent excitatory inputs from acoustic nerve fibers as well as intrinsic and extrinsic inputs from auditory and nonauditory sources (Cant and Benson, 2003; Arnott et al., 2004; Young and Oertel, 2004; Zhou and Shore, 2004). DCN output neurons, especially fusiform cells, receive focused glycinergic input from 
tonotopically aligned vertical cells (Rhode, 1999) and less frequency-focused inhibitory inputs from glycinergic D-multipolar cells in the ventral cochlear nucleus (Saint-Marie et al., 1991; Kolston et al., 1992: Doucet et al., 1999). Vertical cells, termed narrow-band inhibitors, project strong nearcharacteristic frequency (CF) glycinergic inhibition onto fusiform cells (Caspary et al., 1987; Rhode, 1999; Davis and Young, 2000). This inhibition decreases tone-evoked activity in fusiform cells at higher intensities, resulting in flat or nonmonotonic CF rate-level functions (RLFs) termed type III/IV responses (Young and Brownell, 1976; Rhode and Smith, 1986). Nonmonotonic, near-CF rate-level responses are converted to more nearly monotonic functions by glycine receptor blockade (Caspary et al., 1987). In light of neurochemical studies (see Discussion) suggestive of an age-related decrease in glycinergic inhibition in the $\mathrm{DCN}$, the present study examined age-related functional changes in the response properties of putative DCN output neurons. We hypothesize that DCN output neurons, which receive well characterized inhibitory input, would show age-related response changes consistent with a functional loss of inhibition. Furthermore, age-related changes would resemble changes observed with glycine receptor blockade and would alter the output of the cochlear nucleus.

\section{Materials and Methods}

Surgical protocol. Young adult (4-5 months of age) and aged (31-33 months of age) Fischer Brown Norway (FBN) rats were purchased at specified ages from Harlan Sprague Dawley (Indianapolis, IN), which maintains a contract to raise FBN rats for the Office of Biological Resources of the National Institute on Aging. Rats were generally housed for $<1$ month at Southern Illinois University (SIU) and used under protocols approved by the SIU Laboratory Animal Care Committee. The anesthesia protocol was described in detail previously (Palombi and Caspary, 1996). Briefly, young rats were anesthetized with a mixture of ketamine $(75 \mathrm{mg} / \mathrm{kg}$; Aveco, Fort Dodge, IA) and xylazine $(5 \mathrm{mg} / \mathrm{kg}$; Lloyd Laboratories, Shennandoah, IA) along with sodium pentobarbital $(0.10 \mathrm{ml}$ independent of weight; Abbott Laboratories, Abbott Park, IL). Anesthesia was maintained by alternating hourly boosters of ketamine alone $(\sim 33 \mathrm{mg} / \mathrm{kg}$ ) or a ketamine/xylazine mixture (approximately onethird the original dose). Aged rats received lower doses of anesthesia ( $\sim 85 \%$ of the young animal doses) to compensate for reduced liver function (Finlayson and Caspary, 1993; Palombi and Caspary, 1996; Turner et al., 2005). Booster times were similar for young and aged FBN rats, suggesting that the dose adjustment for aged animals was appropriate. Body temperature was maintained at $37^{\circ} \mathrm{C}$ using a thermostatically regulated heating pad.

Rats were placed in an Industrial Acoustic Company (Bronx, NY) sound-attenuating booth. The right pinna and skin reflected from the dorsal surface of the skull were removed. The rat was placed in a stereotaxic frame using a small metal plate attached to the dorsal surface of the skull with bone screws and dental acrylic. The head was rotated $33^{\circ}$ (nose down), and the neck musculature was retracted, exposing the caudal surface of the skull. The occipital bone was partially removed, allowing access to the posterior fossa. Glass micropipettes $(8-16 \mathrm{M} \Omega$ ) filled with either $2 \mathrm{M}$ potassium acetate or horseradish peroxidase (HRP) in $0.5 \mathrm{M}$ $\mathrm{KCl}$ Tris buffer (Sigma, St. Louis, MO) were advanced through the cerebellum into the right DCN.

Acoustic and recording protocol. Acoustic signals were generated by Tucker Davis Technologies (Alachua, FL) System II hardware, amplified (Phase 3 HA-2B amplifier; Videoquip Research, Scarborough, Ontario, Canada), transduced (DT931; Beyerdynamic, Farmingdale, NY), and juxtaposed to the right ear canal using polypropylene tubing. The system was calibrated using a one-quarter inch microphone (model 4938; Bruel \& Kjaer, Naerum, Denmark) and a simulated rat ear (Palombi and Caspary, 1996). Calibration software performed a Fourier analysis on the signal generation system in response to a $1 \mathrm{~V}$ rms click to generate cali- bration tables in decibel sound pressure level (SPL; $20 \mu \mathrm{pa}$ ) for use by programmable attenuators (Windows-based software provided by $\mathrm{K}$. Hancock, Boston University, Boston, MA) (Hancock and Voigt, 2002a,b). Pure tone intensities in decibel SPL were accurate within $2 \mathrm{~dB}$ for frequencies up to $50 \mathrm{kHz}$. Signal generation and data acquisition were controlled by the above software. Search stimuli consisted of 75-85 dB broadband noise pips.

Monaural auditory brainstem responses (ABRs) to broadband noise and $4,8,16$, and $31.5 \mathrm{kHz}$ tones ( $3 \mathrm{~ms}$ duration, $1 \mathrm{~ms} \mathrm{ramp}, 20 / \mathrm{s}$ rate) were obtained from all animals at the beginning of each experiment. Recordings were made from an electrode attached to the apex in the dorsal plate and subcutaneous electrodes in the nose (reference) and neck (ground). Signals were amplified 500,000 times and averaged over 512 trials with hearing thresholds determined visually.

After isolation of a single unit, response maps (one presentation per step) were obtained to determine the CF and threshold. For temporal response classification, poststimulus time histograms (PSTHs) were generated using CF tone bursts ( $5 \mathrm{~ms}$ rise-fall), $30 \mathrm{~dB}$ above $\mathrm{CF}$ threshold from responses to 200 presentations of $50 \mathrm{~ms}$ (1500 bins, $0.075 \mathrm{~ms}$ bin width, $10 \mu$ s resolution) at a rate of $5 / \mathrm{s}$. Spontaneous activity measurements were collected without stimuli as PSTHs above. Data were collected from units judged to be fusiform cells based on previously published criteria from anesthetized preparations (Caspary, 1972; Godfrey et al., 1975; Rhode et al., 1983; Caspary et al., 1994; Backoff et al., 1997; Brozoski et al., 2002). These criteria include the following: (1) putative fusiform-cell recording depths were measured from the cerebellar surface and, when possible, from point of entry into the DCN. A mean depth of $3.52 \mathrm{~mm}$ in young animals and $3.36 \mathrm{~mm}$ in aged animals as measured from the cerebellar surface was equivalent to a depth of $\sim 300 \mu \mathrm{m}$ into the DCN, as determined by the sound produced by the electrode puncturing the overlying pia mater and the simultaneous appearance of a sound-evoked slow-wave; (2) units displaying buildup, pauser-buildup, or broad-chopper responses; and (3) units with large broad triphasic spikes. In most cases, histological verification revealed an electrode track coursing through the fusiform-cell layer with termination of the track shortly beyond the granule cell layer. Because of the curved shape of the DCN and the angle of approach, it was sometimes possible to record from several putative fusiform cells in a single penetration. Electrode penetrations were marked with HRP (4\%, type VI; Sigma) for histological confirmation of recording sites.

Histology. After acquisition of electrophysiological data, animals were given an overdose of anesthetic and perfused transcardially with $0.9 \%$ normal saline, followed by $2.5 \%$ glutaraldehyde in $0.1 \mathrm{M}$ phosphate buffer. The brain was removed, and frozen sections were obtained serially using a sliding microtome. Alternate $40 \mu \mathrm{m}$ sections were stained with thionin. HRP sections were stained for $5 \mathrm{~min}$ at $23^{\circ} \mathrm{C}$ in $0.06 \%$ diaminobenzidine $\mathrm{HCl}$ (Sigma) and mounted on glass microscope slides. HRP marks and electrode tracks were examined to verify recording sites within the DCN (Palombi and Caspary, 1996).

Cochleas from seven of the aged rats were removed, stored in fixative, and sent to Dr. R. Salvi (Center for Hearing and Deafness, State University of New York, Buffalo, NY), who performed inner- and outer-hair cell counts using previously published methods (Boettcher et al., 1992; Spongr et al., 1992). Estimates of inner- and outer-hair cell loss were obtained by comparing hair cell counts from aged FBN rat cochleas to 10 control cochleograms from 10 young-adult animals. Hair cell loss was plotted as a function of distance from the apex and converted to a frequency scale (Greenwood, 1990).

Data analysis. Repeated-measure ANOVA was used to test differences in ABR thresholds. Age (young or old) was treated as a between-subjects variable and stimulus type (noise and 4, 8, 16, and $31.5 \mathrm{kHz}$ tones) and as a within-subject variable. Spike data were imported into an Excel spreadsheet. Peak discharge rates (spikes per second) were obtained from CF and broadband noise RLFs. The highest rate between threshold and 60 $\mathrm{dB}$ above threshold was designated as the maximum evoked firing rate. Rates were calculated from stimulus onset to $5 \mathrm{~ms}$ after stimulus cessation. Dynamic range, expressed in decibels and defined as the intensity range between threshold and peak discharge rate, was obtained from RLF data. Criteria were established to classify RLF shapes into the following 
(A)

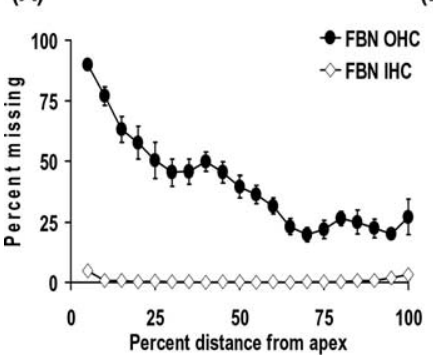

(B)

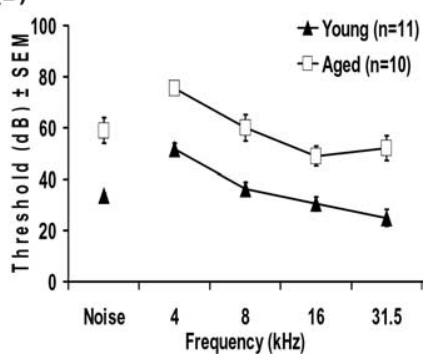

Figure 1. $\quad A$, Cochleograms from aged FBN rats ( 32 months; $n=7$ ) illustrating the percentage of missing hair cells relative to a young-adult rat standard. Aged FBN rats revealed minor inner-hair cell (IHC) loss confined to the extremes of the organ of Corti but significant apical outer-hair cell $(\mathrm{OHC})$ loss that tapered to moderate loss in more basal regions. $\boldsymbol{B}$, ABR thresholds for five conditions $(4,8,16$, and $31.5 \mathrm{kHz}$ ) and broadband noise for young and aged FBN rats (4 months, $n=11 ; 32$ months, $n=10$ ). A significant mean threshold shift of $23 \mathrm{~dB}$ was observed $(p<0.001)$.

five categories: (1) monotonic units that increased the firing rate progressively over the full range of intensities; (2) plateauing units that increased the firing rate over low intensities but stabilized the firing rate at higher intensities to remain within $10 \%$ of the peak rate; (3) nonmonotonic units that showed an increased firing rate to a maxima and a decreased discharge rate by $\geq 10 \%$ at higher intensities; (4) downward-sloping units that exhibited peak rates near threshold that progressively decreased as intensity increased; and (5) complex-RLF units that did not fit any other pattern and produced rates that often increased and decreased several times over the intensity range. Temporal responses were visually classified into one of four categories based on qualitative descriptions (adapted from Pfeiffer, 1966; Caspary, 1972; Brozoski et al., 2002): (1) pauser units displayed a clear onset peak, followed by a pause and resumption of steady or increasing discharge rate as the stimulus progressed in time; (2) buildup units lacked a clear onset peak, had a long first-spike latency, and showed an increasing discharge rate as the stimulus progressed over time; (3) wide-chopper units exhibited broad, regular firing patterns forming visible peaks that became steady or increased toward the end of the signal; and (4) atypical units produced PSTHs similar to the pauser pattern but had a double peak at onset, a second peak after the pause, or an incomplete pause. Young and aged rat DCN output neuron populations were compared using ANOVA, Fisher's exact, and $\chi^{2}$ tests.

\section{Results}

Age-related comparisons were made between 94 putative DCN fusiform cells from 15 young-adult FBN rats (4-5 months of age) and 90 putative DCN fusiform cells from 16 aged FBN rats (31-33 months of age).

\section{Age-related cochlear changes}

The average hair cell loss from a sample of seven aged FBN rat cochleas was compared with cochleograms from young-adult animals. Age-related outer-hair cell loss as high as 90\% occurred within the most apical 5\% of the organ of Corti. An age-related loss of $<1 \%$ of inner-hair cells was observed throughout the middle turns of the cochlea, with only $3-5 \%$ missing at the apical and basal extremes of aged cochleas (Fig. 1A).

\section{Age-related ABR threshold changes}

ABRs were obtained from all animals in response to 4, 8, 16, and 31.5 $\mathrm{kHz}$ and broadband noise (Fig. $1 B$ ). Young and aged rats showed progressively lower thresholds as stimulus frequency increased (Fig. 1B). Aged rats had significantly higher mean thresholds $(p<0.001)$ across all frequencies tested (Fig. 1B). The threshold was elevated $\sim 23 \mathrm{~dB}$ across frequencies. Although there were significant effects for both age

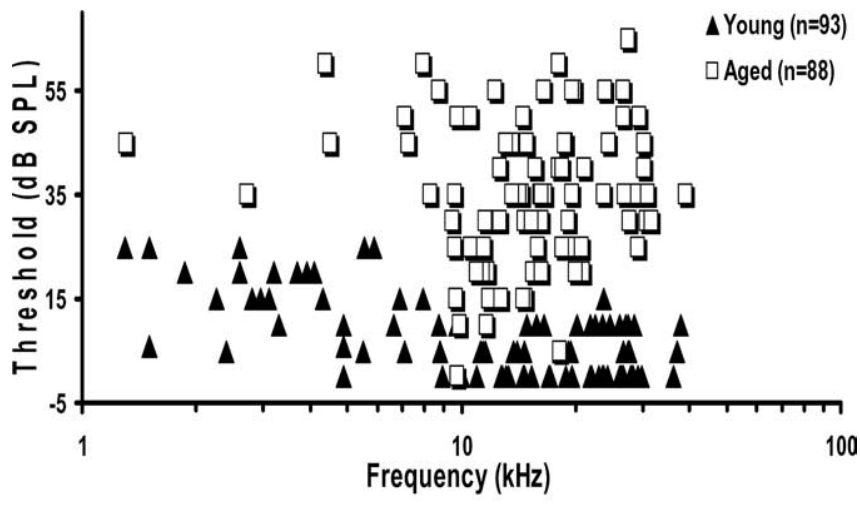

Age variance $p<0.005$, F-test

Figure 2. CF thresholds, in $93 \mathrm{U}$ from young putative fusiform cells and $88 \mathrm{U}$ from old putative fusiform cells, showed a $27 \mathrm{~dB}$ mean threshold shift. When these data were placed into frequency bins, a significant age-related change was observed in the frequency distribution $(p<0.01)$. Fewer aged units were encountered at either frequency extreme, with the majority having CFs between 10 and $20 \mathrm{kHz}$.

and stimuli $(p<0.001)$, we failed to find an interaction between the two variables $(p=0.38)$. The lack of an interaction between age and stimuli indicates a parallel upward shift in threshold across all frequencies.

\section{Age-related changes in CF distribution and thresholds}

Response maps were used to determine CF and threshold at CFs for each unit. The mean CF was not significantly different between the two age groups (young, $15.65 \pm 1.03$; aged, $16.53 \pm$ $0.79)$. The variance of CFs for all DCN neurons examined was significantly reduced $(p<0.01)$ in the aged group (Fig. 2$)$. When the scatter plot data were placed into frequency bins, fewer aged units were encountered at the frequency extremes. The aged CF distribution differed significantly from the young CF distribution $(p<0.01)$ in that the majority of aged units had CFs between 10 and $20 \mathrm{kHz}$. Single-unit thresholds were also higher in aged rats $(p<0.001)$. Young rat thresholds ranged from 0 to $25 \mathrm{~dB}$ SPL with a mean of $7.5 \mathrm{~dB}$ SPL, whereas aged animals had thresholds that ranged from 0 to $65 \mathrm{~dB}$ SPL with a mean of $35 \mathrm{~dB}$ SPL. Single-unit thresholds across frequencies were qualitatively similar to the ABR threshold pattern, as were age-related changes in single unit thresholds. Aged animals showed $\sim 27 \mathrm{~dB}$ higher thresholds and relatively uniform changes across frequency.

\section{Evidence for a loss of inhibition/age-related rate versus level changes}

As postulated, aging increased the CF sound-evoked maximum discharge rate. However, the maximum discharge rate significantly increased with age in response to both CF tones and broadband noise (Table 1). For putative fusiform cells, there was a significant age-related increase in the average maximum discharge rate evoked by CF tones $(p<0.01)$ and by broadband noise $(p<0.001)$ (Table 1$)$. CF tones evoked higher firing rates than broadband noise with $94 \%$ of young fusiform cells and $86.4 \%$ of aged neurons displaying higher maximum evoked rates to the CF than to noise. This difference was only marginally significant $(p=0.063)$. The increase in the firing rate of neurons to CF tone bursts versus noise was of approximately the same magnitude for young and aged neurons $(p=0.91)$.

This age-related increase in the maximum discharge rate reflected an age-related change in RLF shape for CF tones but not for noise. CF-evoked RLFs from the entire set of young and aged neurons showing fusiform-like response properties were normal- 


\begin{tabular}{|c|c|c|c|c|c|c|c|}
\hline & \multicolumn{3}{|l|}{ Young } & \multicolumn{3}{|l|}{ Aged } & \multirow{2}{*}{$\begin{array}{l}t \text { test } \\
p \text { values }\end{array}$} \\
\hline & Mean & SEM & $n$ & Mean & SEM & $n$ & \\
\hline Maximum (F-evoked firing rate (spikes/s) & 89.97 & 3.51 & 91 & 105.75 & 4.02 & 88 & 0.0035 \\
\hline CF dynamic range $(\mathrm{dB})$ & 26.92 & 2.08 & 91 & 33.75 & 2.07 & 85 & 0.0211 \\
\hline Maximum noise-evoked firing rate (spikes/s) & 60.16 & 2.89 & 91 & 75.50 & 3.22 & 88 & 0.001 \\
\hline Spontaneous firing rate (spikes/s) & 36.79 & 1.88 & 90 & 40.88 & 1.91 & 85 & 0.13 \\
\hline
\end{tabular}

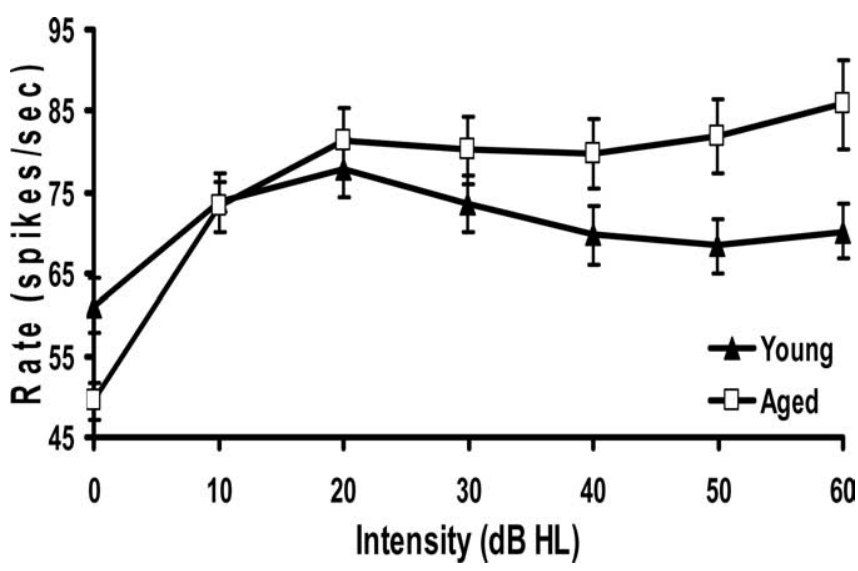

Figure 3. Composite RLFs for young ( $n=91)$ and aged $(n=88)$ neurons were created from the mean $( \pm S E M)$ rate at each intensity relative to hearing threshold. There was a significant age-related difference between these two composite functions (see Results). The greatest agerelated changes occurred at the highest intensities at which inhibition is the greatest. The composite RLF for young neurons peaked at $20 \mathrm{~dB}$ above threshold and decreased, which is a characteristic of DCN fusiform cells. However, the aged neuron population showed a more monotonic rate response. HL, Hearing level.

ized to threshold regarding the decibel hearing level and compared. Figure 3 shows a significant age-related change in the shape of the composite RLFs, with the greatest changes occurring at the highest intensities tested. The nonmonotonic composite RLF from young fusiform cells converted to a more monotonic composite RLF in aged animals (Fig. 3). This age-related RLF shape change may reflect a loss of glycinergic inhibition at the highest intensities.

The shape of individual RLFs from young and aged neurons was visually classified as described in Materials and Methods. A majority of putative DCN fusiform cells from young rats responded to increasing CF tone levels with nonmonotonic RLFs (57.1\%). Fewer DCN neurons from young animals showed plateauing or monotonic RLFs in response to CF tones (14.3 and $6.6 \%$, respectively), with remaining DCN units split relatively evenly into the other categories (Fig. 4). There was a significant age-related change in CF-evoked RLF shape distribution $(p<$ 0.01 ). Aged DCN output neurons were significantly less likely to display nonmonotonic CF tone RLFs (44.3 vs $57.1 \%$ ) and more likely to show plateauing ( 27.3 vs $14.3 \%$ ) or monotonic (14.8 vs $6.6 \%)$ RLFs than young neurons (Fig. 4). Broadband noiseevoked RLFs were categorized using the same criteria as for CF tones. Noise-evoked RLFs were more evenly distributed between nonmonotonic, monotonic, and plateauing RLF types (Fig. 4). There were no significant age-related changes in the noiseevoked RLF shape distribution ( $p=0.96$ ) (Fig. 4), possibly reflecting loss of inhibitory input from neurons showing lowthreshold monotonic responses to broadband stimuli.
Age-related changes in the distribution of temporal responses (PSTH types)

Temporal responses of putative DCN fusiform cells to CF tonal stimuli were collected at $30 \mathrm{~dB}$ above $\mathrm{CF}$ threshold and classified into four PSTH categories: pauser, buildup, wide-chopper, and atypical (Fig. 5). A significant $(p<0.001)$ age-related change in the distribution of temporal response PSTH types was observed from putative fusiform cells in the DCN (Fig. 5). Young-adult rat DCN putative fusiform cells displayed pauser PSTHs (64.5\%), with smaller numbers of neurons showing wide-chopper and buildup responses (17.2 and 12.9\%, respectively) (Fig. 5). There was a significant age-related reduction in the number of pauser neurons ( 35.2 vs $64.5 \%$ ), with greater numbers of wide-chopper (34.1 vs $17.2 \%$ ) and buildup (21.6 vs $12.9 \%$ ) PSTH response types in aged DCNs (Fig. 5).

\section{Aging effects on spontaneous activity}

Spontaneous activity (spikes per second) was calculated for each unit during 200 trials of $200 \mathrm{~ms}$ duration. The mean spontaneous rate was higher in older $(36.79 \pm 1.88)$ than younger $(33.75 \pm$ 2.07) DCN output neurons, but this increase failed to achieve the traditional significance level $(p=0.13)$.

\section{Discussion}

The present findings support the hypothesis that an age-related loss of normal adult glycinergic inhibitory neurotransmission alters the response properties of DCN fusiform cells (Nelken and Young, 1994; Zhang and Oertel, 1994). One major source of glycinergic inhibition arises from vertical cells, which inhibit responses to narrow-band stimuli (Voigt and Young, 1980, 1990; Caspary et al., 1987; Saint-Marie et al., 1991; Spirou et al., 1999).

Findings of an age-related increase in near-CF dynamic range, a decreased number of neurons displaying nonmonotonic RLFs, and an increase in wide-chopper temporal response patterns resemble changes observed when glycinergic inputs onto fusiform cells from high-threshold vertical cells are blocked (Caspary et al., 1987; Davis and Young, 2000).

Age-related hearing loss can be thought of as a slow peripheral deafferentation, and the present findings are consistent with a number of partial deafferentation models using acoustic trauma, disarticulation, and, to a lesser extent, cochlear destruction (Suneja et al., 1998a,b; Kaltenbach and Afman, 2000; Kaltenbach et al., 2000; Milbrandt et al., 2000; Potashner et al., 2000; Brozoski et al., 2002; Asako et al., 2005). Aged rodents exhibit a number of age-related peripheral auditory changes, including a sloping lowfrequency loss of outer-hair cells and a small loss of apical and basal inner-hair cells (for review, see Willott, 1991; Saitoh et al., 1994; Gratton et al., 1996, 1997; Spongr et al., 1997; Ingham et al., 1999; Turner and Caspary, 2005) and auditory nerve fiber loss (Keithley et al., 1989, 1992; Dazert et al., 1996; Schmiedt et al., 1996). As in the present study, decreased acoustic nerve input activity into the DCN resulted in neurochemical evidence of a downregulation of putative glycinergic inhibition (Potashner et 
al., 1997; Suneja et al., 1998a,b; Caspary et al., 2002). Brozoski et al. (2002) recorded from putative DCN fusiform cells in animals showing modest cochlear damage from acoustic trauma. As in the present aging study, Brozoski et al. (2002) found that putative fusiform cell responses from noise-exposed chinchilla DCN showed increased near-CF dynamic range and fewer nonmonotonic CF RLFs. However, unlike Brozoski et al. (2002), who demonstrated a significant increase in spontaneous activity in the fusiform cells from tinnitus animals, the present study found only a trend toward increased spontaneous activity in the aged DCN. This lack of a significant age-related change in spontaneous rate is still consistent with the hypothesis of an age-related decrease in glycine, because both vertical and D-multipolar cells show little or no spontaneous activity. Altered inputs onto fusiform cells from these inhibitory neurons would not be expected to significantly alter fusiform spontaneous rates.

Previous DCN aging studies described decreased glycine levels, decreased strychnine binding (especially in the fusiform layer), and a loss of glycine immunoreactivity in cells at the junction between the deep and fusiform-cell layers of the cochlear nucleus (Banay-Schwartz et al., 1989; Willott et al., 1997; Milbrandt et al., 2000; Caspary et al., 2001). The subunit makeup of the glycine receptor showed age-related changes, in both the DCN and AVCN, that could account for functional changes observed in the present study (Krenning et al., 1998; Caspary et al., 2002). Age-related loss of markers for inhibitory amino acids has also been described for the auditory midbrain. The inferior colliculus (IC) shows significant age-related changes related to GABA neurotransmission in rats (Banay-Schwartz et al., 1989; Caspary et al., 1990, 1995; Gutierrez et al., 1994; Milbrandt et al., 1994; Raza et al., 1994) and the loss of GABAimmunoreactive synaptic endings. Postmortem human studies of the cortex and IC are less clear. McGeer and McGeer (1980) described age-related losses of glutamic acid decarboxylase in the cortex and IC, whereas a second study failed to detect significant age-related changes of GABA levels in the IC (Banay-Schwartz et al., 1993).

Either loss of presynaptically released glycine or glycine receptors with altered sensitivity could account for the observed agerelated changes in dynamic range/loss of nonmonotonic rate functions. These age-related changes resemble those observed when glycine receptors are blocked by iontophoretic application of a glycine receptor antagonist, strychnine (Caspary et al., 1987; Davis and Young, 2000).

Both in vivo and in vitro intracellular studies demonstrate resting potential-dependant changes in the temporal pattern of re- sponses evoked by current or CF tone bursts. In an impressive series of in vivo intracellular recording studies from subsequently labeled fusiform cells, Rhode and Smith (1986) found that the degree of membrane hyperpolarization determined the temporal response pattern to above-threshold CF tone bursts. At high negative resting potential values, buildup responses were evoked by CF tone-burst stimulation. At more depolarized values, first pauser-buildup, then pauser, and finally wide-chopper temporal patterns were observed (Rhode and Smith, 1986). Similar observations by Manis (1990) were noted in an in vitro DCN preparation. This investigator found that the temporal response pattern evoked by a depolarizing intracellular current was determined by the level of hyperpolarization. Kim et al. (1994) developed a computational model of fusiform responses in the DCN in which type "A" potassium conductance played an essential role in the gener- 

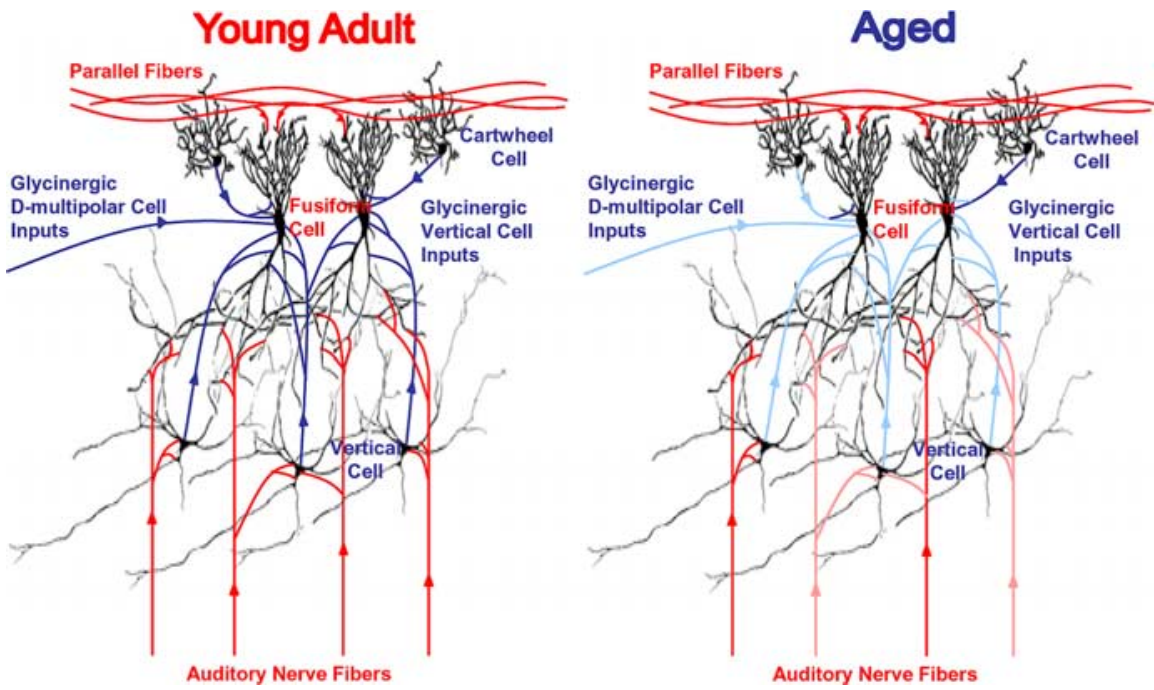

Figure 6. Diagram of the DCN circuit in young and aged rats. The blue pathways represent two inhibitory glycine circuits within the DCN. Findings from the present study suggest a selective loss of inhibitory input from vertical cells, narrow-band inhibition, and a less selective loss of inhibition from D-multipolar cells, wide-band inhibition, in the DCN of old animals. These circuits are represented by faded blue lines in the aged diagram likely representing a loss of functional glycinergic input onto DCN output neurons from vertical and D-multipolar cells (see Discussion).

ation of buildup and pauser response patterns. More recently, Kanold and Manis (2001) developed a physiologically based model of discharge pattern regulation as a function of transient potassium currents in cochlear nucleus pyramidal cells.

The present study found a significant age-related increase in the proportion of aged neurons classified as wide chopper and a corresponding decrease in the proportion of pauser types. The change in temporal response type is consistent with an agerelated loss of membrane hyperpolarization perhaps attributable to an age-related loss of tonic glycinergic input onto fusiform cells. Collectively, these findings suggest an age-related loss, primarily of glycinergic narrow-band inhibition onto DCN fusiform cells (Fig. 6). However, the age-related increase in the maximum discharge rate evoked by broadband noise is not entirely consistent with a selective age-related decrement in vertical cell function. DCN fusiform cells also receive input from a wide-band inhibitor that responds to broadband noise and can inhibit vertical cells (Nelken and Young, 1994; Winter and Palmer, 1995; Doucet and Ryugo, 1997; Doucet et al., 1999; Young and Oertel, 2004). Narrow-band and wide-band inhibitory systems display differential sensitivities to anesthetics (Anderson and Young, 2003), suggesting that compensatory age-related plastic changes might differentially affect these two inhibitory systems. Although we observed an age-related change in the dynamic range and maximum discharge rate evoked by both broadband noise and $\mathrm{CF}$ tones, there were no age-related changes in the shape of individual RLFs evoked by noise (Fig. 4). A parallel nonselective shift in the fusiform cell discharge rate in response to broadband stimuli would be expected if the inhibitory inputs originated from neurons with linear RLFs and a low-threshold broadband stimuli. Thus, it is probable that the higher maximum discharge rate and change in RLF shape in response to narrow-band near-CF stimuli observed when recording from aged fusiform cells is a reflection of the loss of glycinergic inhibition from vertical cells. In contrast, changes in aged putative fusiform cell responses to broadband stimuli may, in fact, represent altered input from the wide-band inhibitor, the D-multipolar cells of the ventral cochlear nucleus.
In conclusion, the findings of this study present compelling evidence that aging results in a selective downregulation of glycinergic inhibitory processing in the DCN (Fig. 6). This age-related downregulation of glycinergic inhibition alters the fusiform-cell output of DCNs but also likely alters the AVCN output based on AVCN neurochemical and slice studies (Milbrandt and Caspary, 1995; Wicksberg, 1996; Krenning et al., 1998). The loss of nonmonotonic fusiform-cell output likely has an impact on IC neurons (Davis et al., 2003). Aged IC neurons display more monotonic RLFs. This is likely attributable to altered inhibitory processing in the IC as well as increased excitation at higher intensities from DCN input (Palombi and Caspary, 1996). Thus, the age-related loss of acoustic nerve activity seems to result in a compensatory downregulation in the function of the glycinergic backbone/control system of the cochlear nucleus. Altered output from the cochlear nucleus could lead to a decrease in the ability to adjust dynamic range, a classic symptom of age-related hearing loss in the elderly.

\section{References}

Anderson MJ, Young ED (2003) Isoflurane/N2O anesthesia suppresses narrow-band but not wide-band inhibition in dorsal cochlear nucleus. Hear Res 188:29-41.

Arnott RH, Wallace MN, Shackleton TM, Palmer AR (2004) Onset neurones in the anteroventral cochlear nucleus project to the dorsal cochlear nucleus. J Assoc Res Otolaryngol 5:153-170.

Asako M, Holt AG, Griffith RD, Buras ED, Altschuler RA (2005) Deafnessrelated decreases in glycine-immunoreactive labeling in the rat cochlear nucleus. J Neurosci Res 81:102-109.

Backoff PM, Palombi PS, Caspary DM (1997) Glycinergic and GABAergic inputs affect short-term suppression in the cochlear nucleus. Hear Res 110:155-163.

Banay-Schwartz M, Lajtha A, Palkovits M (1989) Changes with aging in the levels of amino acids in rat CNS structural elements. II. Taurine and small neutral amino acids. Neurochem Res 14:563-570.

Banay-Schwartz M, Palkovits M, Lajtha A (1993) Heterogeneous distribution of functionally important amino acids in brain areas of adult and aging humans. Neurochem Res 18:417-423.

Boettcher FA, Spongr VP, Salvi RJ (1992) Physiological and histological changes associated with the reduction in threshold shift during interrupted noise exposure. Hear Res 62:217-236.

Brozoski TJ, Bauer CA, Caspary DM (2002) Elevated fusiform-cell activity in the dorsal cochlear nucleus of chinchillas with psychophysical evidence of tinnitus. J Neurosci 22:2383-2390.

Cant NB, Benson CG (2003) Parallel auditory pathways: projection patterns of the different neuronal populations in the dorsal and ventral cochlear nuclei. Brain Res Bull 60:457-474.

Caspary DM (1972) Classification of subpopulations of neurons in the cochlear nuclei of the kangaroo rat. Exp Neurol 37:131-151.

Caspary DM, Pazara KE, Kossl M, Faingold CL (1987) Strychnine alters the fusiform cell output from the dorsal cochlear nucleus. Brain Res 417:273-282.

Caspary DM, Raza A, Lawhorn Armour BA, Pippin J, Arneric SP (1990) Immunocytochemical and neurochemical evidence for age-related loss of GABA in the inferior colliculus: implications for neural presbycusis. J Neurosci 10:2363-2372.

Caspary DM, Backoff PM, Finlayson PG, Palombi PS (1994) Inhibitory inputs modulate discharge rate within frequency receptive fields of anteroventral cochlear nucleus. J Neurophysiol 72:2124-2133. 
Caspary DM, Milbrandt JC, Helfert RH (1995) Central auditory aging: GABA changes in the inferior colliculus. Exp Gerontol 30:349-360.

Caspary DM, Salvi RJ, Helfert RH, Brozoski TJ, Bauer CA (2001) Neuropharmacology of noise induced hearing loss in brainstem auditory structures. In: Noise induced hearing loss: mechanisms of damage and means of prevention (Henderson D, Prasher D, Kopke R, Salvi RJ, Hamernik R, eds), pp 169-186. London: NRN.

Caspary DM, Palombi PS, Hughes LF (2002) GABAergic inputs shape responses to amplitude modulated stimuli in the inferior colliculus. Hear Res 168:163-173.

Davis KA, Young ED (2000) Pharmacological evidence of inhibitory and disinhibitory neuronal circuits in dorsal cochlear nucleus. J Neurophysiol 83:926-940.

Davis KA, Ramachandran R, May BJ (2003) Auditory processing of spectral cues for sound localization in the inferior colliculus. J Assoc Res Otolaryngol 4:148-163.

Dazert S, Feldman ML, Keithley EM (1996) Cochlear spiral ganglion cell degeneration in wild-caught mice as a function of age. Hear Res 100:101-106.

Doucet JR, Ryugo DK (1997) Projections from the ventral cochlear nucleus to the dorsal cochlear nucleus in rats. J Comp Neurol 385:245-264.

Doucet JR, Ross AT, Gillespie MB, Ryugo DK (1999) Glycine immunoreactivity of multipolar neurons in the ventral cochlear nucleus which project to the dorsal cochlear nucleus. J Comp Neurol 408:515-531.

Dubno JR, Dirks DD, Morgan DE (1984) Effects of age and mild hearing loss on speech recognition in noise. J Acoust Soc Am 76:87-96.

Finlayson PG, Caspary DM (1993) Response properties in young and old Fischer 344 rat lateral superior olive neurons: a quantitative approach. Neurobiol Aging 14:127-139.

Fitzgibbons PJ, Gordon-Salant S (1994) Age effects on measures of auditory duration discrimination. J Speech Hear Res 37:662-670.

Frisina DR, Frisina RD (1997) Speech recognition in noise and presbycusis: relations to possible neural mechanisms. Hear Res 106:95-104.

Frisina RD, Walton JP, Karcich KJ (1994) Dorsal cochlear nucleus single neurons can enhance temporal processing capabilities in background noise. Exp Brain Res 102:160-164.

Gibson DJ, Young ED, Costalupes JA (1985) Similarity of dynamic range adjustment in auditory nerve and cochlear nuclei. J Neurophysiol 53:940-958.

Godfrey DA, Kiang NY, Norris BE (1975) Single unit activity in the dorsal cochlear nucleus of the cat. J Comp Neurol 162:269-284.

Gordon-Salant S, Fitzgibbons PJ (1993) Temporal factors and speech recognition performance in young and elderly listeners. J Speech Hear Res 36:1276-1285.

Gratton MA, Schmiedt RA, Schulte BA (1996) Age-related decreases in endocochlear potential are associated with vascular abnormalities in the stria vascularis. Hear Res 102:181-190.

Gratton MA, Schulte BA, Smythe NM (1997) Quantification of the stria vascularis and strial capillary areas in quiet-reared young and aged gerbils. Hear Res 114:1-9.

Greenwood DD (1990) A cochlear frequency-position function for several species-29 years later. J Acoust Soc Am 87:2592-2605.

Gutierrez A, Khan ZU, Morris SJ, De Blas AL (1994) Age-related decrease of $\mathrm{GABA}_{\mathrm{A}}$ receptor subunits and glutamic acid decarboxylase in the rat inferior colliculus. J Neurosci 14:7469-7477.

Hancock KE, Voigt HF (2002a) Intracellularly labeled fusiform cells in dorsal cochlear nucleus of the gerbil. I. Physiological response properties. J Neurophysiol 87:2505-2519.

Hancock KE, Voigt HF (2002b) Intracellularly labeled fusiform cells in dorsal cochlear nucleus of the gerbil. II. Comparison of physiology and anatomy. J Neurophysiol 87:2520-2530.

Ingham NJ, Comis SD, Withington DJ (1999) Hair cell loss in the aged guinea pig cochlea. Acta Otolaryngol 119:42-47.

Joris PX, Schreiner CE, Rees A (2003) Neural processing of amplitude modulated sounds. Physiol Rev 84:541-577.

Kaltenbach JA, Afman CE (2000) Hyperactivity in the dorsal cochlear nucleus after intense sound exposure and its resemblance to tone-evoked activity: a physiological model for tinnitus. Hear Res 140:165-172.

Kaltenbach JA, Zhang J, Afman CE (2000) Plasticity of spontaneous neural activity in the dorsal cochlear nucleus after intense sound exposure. Hear Res 147:282-292.

Kanold PO, Manis PB (2001) A physiologically based model of discharge pattern regulation by transient $\mathrm{K}^{+}$currents in cochlear nucleus pyramidal cells. J Neurophysiol 85:523-538.

Keithley EM, Ryan AF, Woolf NK (1989) Spiral ganglion cell density in young and old gerbils. Hear Res 38:125-133.

Keithley EM, Ryan AF, Feldman ML (1992) Cochlear degeneration in aged rats of four strains. Hear Res 59:171-178.

Kim DO, Ghoshal S, Khant SL, Parham K (1994) A computational model with ionic conductances for the fusiform cell of the dorsal cochlear nucleus. J Acoust Soc Am 96:1501-1514.

Kolston J, Osen KK, Hackney CM, Ottersen OP, Storm-Mathisen J (1992) An atlas of glycine- and GABA-like immunoreactivity and colocalization in the cochlear nuclear complex of the guinea pig. Anat Embryol (Berl) 186:443-465.

Krenning J, Hughes LF, Caspary DM, Helfert RH (1998) Age-related glycine receptor subunit changes in the cochlear nucleus of Fischer-344 rats. Laryngoscope 108:26-31.

Leventhal AG, Wang Y, Pu M, Zhou Y, Ma Y (2003) GABA and its agonists improved visual cortical function in senescent monkeys. Science 300:812-815.

Manis PB (1990) Membrane properties and discharge characteristics of guinea pig dorsal cochlear nucleus neurons studied in vitro. J Neurosci 10:2338-2351.

McGeer EG, McGeer PL (1980) Aging and neurotransmitter systems. Adv Biochem Psychopharmacol 23:305-314.

Mendelson JR, Ricketts C (2001) Age-related temporal processing speed deterioration in auditory cortex. Hear Res 158:84-94.

Milbrandt JC, Caspary DM (1995) Age-related reduction of $\left[{ }^{3} \mathrm{H}\right]$ strychnine binding sites in the cochlear nucleus of the Fischer 344 rat. Neuroscience 67:713-719.

Milbrandt JC, Albin RL, Caspary DM (1994) Age-related decrease in GABAB receptor binding in the Fischer 344 rat inferior colliculus. Neurobiol Aging 15:699-703.

Milbrandt JC, Holder TM, Wilson MC, Salvi RJ, Caspary DM (2000) GAD levels and muscimol binding in rat inferior colliculus following acoustic trauma. Hear Res 147:251-260.

Moore BC, Peters RW, Glasberg BR (1992) Detection of temporal gaps in sinusoids by elderly subjects with and without hearing loss. J Acoust Soc Am 92:1923-1932.

Mulrow CD, Aguilar C, Endicott JE, Tuley MR, Velez R, Charlip WS, Rhodes MC, Hill JA, DeNino LA (1990) Quality-of-life changes and hearing impairment: a randomized trial. Ann Intern Med 113:188-194.

Nelken I, Young ED (1994) Two separate inhibitory mechanisms shape the responses of dorsal cochlear nucleus type IV units to narrow-band and wide-band stimuli. J Neurophysiol 71:2446-2462.

Ostroff JM, McDonald KL, Schneider BA, Alain C (2003) Aging and the processing of sound duration in human auditory cortex. Hear Res 181:1-7.

Palombi PS, Caspary DM (1996) Physiology of the aged Fischer 344 rat inferior colliculus: responses to contralateral monaural stimuli. J Neurophysiol 76:3114-3125.

Pfeiffer RR (1966) Classification of response patterns of spike discharges for units in the cochlear nucleus: tone-burst stimulation. Exp Brain Res 1:220-235.

Potashner SJ, Suneja SK, Benson CG (1997) Regulation of D-aspartate release and uptake in adult brain stem auditory nuclei after unilateral middle ear ossicle removal and cochlear ablation. Exp Neurol 148:222-235.

Potashner SJ, Suneja SK, Benson CG (2000) Altered glycinergic synaptic activities in guinea pig brain stem auditory nuclei after unilateral cochlear ablation. Hear Res 147:125-136.

Raza A, Milbrandt JC, Arneric SP, Caspary DM (1994) Age-related changes in brainstem auditory neurotransmitters: measures of GABA and acetylcholine function. Hear Res 77:221-230.

Rhode WS (1999) Vertical cell responses to sound in cat dorsal cochlear nucleus. J Neurophysiol 82:1019-1032.

Rhode WS, Greenberg S (1994) Encoding of amplitude modulation in the cochlear nucleus of the cat. J Neurophysiol 71:1797-1825.

Rhode WS, Smith PH (1986) Physiological studies on neurons in the dorsal cochlear nucleus of cat. J Neurophysiol 56:287-307.

Rhode WS, Oertel D, Smith PH (1983) Physiological response properties of cells labeled intracellularly with horseradish peroxidase in cat ventral cochlear nucleus. J Comp Neurol 213:448-463.

Saint-Marie RL, Benson CG, Ostapoff EM, Morest DK (1991) Glycine im- 
munoreactive projections from the dorsal to the anteroventral cochlear nucleus. Hear Res 51:11-28.

Saitoh Y, Hosokawa M, Shimada A, Watanabe Y, Yasuda N, Takeda T, Murakami Y (1994) Age-related hearing impairment in senescenceaccelerated mouse (SAM). Hear Res 75:27-37.

Schmiedt RA, Mills JH, Boettcher FA (1996) Age-related loss of activity of auditory-nerve fibers. J Neurophysiol 76:2799-2803.

Schmolesky MT, Wang Y, Pu M, Leventhal AG (2000) Degradation of stimulus selectivity of visual cortical cells in senescent rhesus monkeys. Nat Neurosci 3:384-390.

Schneider BA, Pichora-Fuller MK, Kowalchuk D, Lamb M (1994) Gap detection and the precedence effect in young and old adults. J Acoust Soc Am 95:980-991.

Snell KB (1997) Age-related changes in temporal gap detection. J Acoust Soc Am 101:2214-2220.

Spirou GA, Davis KA, Nelken I, Young ED (1999) Spectral integration by type II interneurons in dorsal cochlear nucleus. J Neurophysiol 82:648-663.

Spongr VP, Boettcher FA, Saunders SS, Salvi RJ (1992) Effects of noise and salicylate on hair cell loss in the chinchilla cochlea. Arch Otolaryngol Head Neck Surg 118:157-164.

Spongr VP, Flood DG, Frisina RD, Salvi RJ (1997) Quantitative measures of hair cell loss in CBA and C57BL/6 mice throughout their life spans. J Acoust Soc Am 101:3546-3553.

Strouse A, Ashmead DH, Ohde RN, Grantham DW (1998) Temporal processing in the aging auditory system. J Acoust Soc Am 104:2385-2399.

Suneja SK, Potashner SJ, Benson CG (1998a) Plastic changes in glycine and GABA release and uptake in adult brain stem auditory nuclei after unilateral middle ear ossicle removal and cochlear ablation. Exp Neurol 151:273-288.

Suneja SK, Benson CG, Potashner SJ (1998b) Glycine receptors in adult guinea pig brain stem auditory nuclei: regulation after unilateral cochlear ablation. Exp Neurol 154:473-488.

Syka J (2002) Plastic changes in the central auditory system after hearing loss, restoration of function, and during learning. Physiol Rev 82:601-636.

Thomas A, Herbst KG (1980) Social and psychological implications of acquired deafness for adults of employment age. Br J Audiol 14:76-85.

Tremblay KL, Piskosz M, Souza P (2002) Aging alters the neural representation of speech cues. NeuroReport 13:1865-1870.
Tremblay KL, Piskosz M, Souza P (2003) Effects of age and age-related hearing loss on the neural representation of speech cues. Clin Neurophysiol 114:1332-1343.

Turner JG, Caspary DM (2005) Comparison of two rat models of aging. In: Plasticity and signal representation in the auditory system (Syka J, Merzenich MM, eds) pp 217-225. New York: Springer.

Turner JG, Hughes LF, Caspary DM (2005) Divergent response properties of layer-V neurons in rat primary auditory cortex. Hear Res 202:129-140.

Voigt HF, Young ED (1980) Evidence of inhibitory interactions between neurons in dorsal cochlear nucleus. J Neurophysiol 44:76-96.

Voigt HF, Young ED (1990) Cross-correlation analysis of inhibitory interactions in dorsal cochlear nucleus. J Neurophysiol 64:1590-1610.

Weinstein BE, Ventry IM (1982) Hearing impairment and social isolation in the elderly. J Speech Hear Res 25:593-599.

Wicksberg RE (1996) Rapid inhibition in the cochlear nuclear complex of the chinchilla. J Acoust Soc Am 100:1691-1702.

Willott JF (1991) Aging and the auditory system. San Diego: Singular.

Willott JF, Parham K, Hunter KP (1991) Comparison of the auditory sensitivity of neurons in the cochlear nucleus and inferior colliculus of young and aging C57BL/6J and CBA/J mice. Hear Res 53:78-94.

Willott JF, Milbrandt JC, Bross LS, Caspary DM (1997) Glycine immunoreactivity and receptor binding in the cochlear nucleus of C57BL/6J and $\mathrm{CBA} / \mathrm{CaJ}$ mice: effects of cochlear impairment and aging. J Comp Neurol 385:405-414.

Winter IM, Palmer AR (1995) Level dependence of cochlear nucleus onset unit responses and facilitation by second tones or broadband noise. J Neurophysiol 73:141-159.

Young ED, Brownell WE (1976) Responses to tones and noise of single cells in dorsal cochlear nucleus of unanesthetized cats. J Neurophysiol 39:282-300.

Young ED, Oertel D (2004) Cochlear nucleus. In: The synaptic organization of the brain (Shepherd GM, ed), pp 125-163. New York: Oxford UP.

Zhang S, Oertel D (1994) Neuronal circuits associated with the output of the dorsal cochlear nucleus through fusiform cells. J Neurophysiol 71:914-930.

Zhou J, Shore S (2004) Projections from the trigeminal nuclear complex to the cochlear nuclei: a retrograde and anterograde tracing study in the guinea pig. J Neurosci Res 78:901-907. 